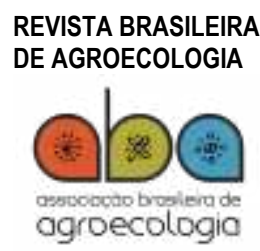

ISSN: $1980-9735$

\title{
EDIÇÃO ESPECIAL DA REVISTA BRASILEIRA DE AGROECOLOGIA: TECENDO O XI CONGRESSO BRASILEIRO DE AGROECOLOGIA
}

\author{
Luiza Morelli Damigo', Natália Almeida de Sousa² e Romier da Paixão Sousa ${ }^{3}$
}

Esta Edição Especial, da Revista Brasileira de Agroecologia (RBA) acolhe artigos produzidos em parceria com grupos de pesquisa que têm o campo fértil de conhecimentos da Agroecologia como fonte de suas análises, cujas reflexões apresentadas vão ao encontro do processo preparatório do XI Congresso Brasileiro de Agroecologia (CBA).

Dedicamos este editorial a convidar instituições de ensino, pesquisa e extensão, núcleos e grupos de agroecologia, estudantes, pesquisadoras(es), profissionais, movimentos sociais, famílias agricultoras, povos indígenas, comunidades tradicionais e demais companheiras(os) para o XI CBA, realizado pela segunda vez na Região Nordeste, no Estado de Sergipe.

Escrever sobre o CBA é trazer na memória o acúmulo de muitos processos coletivos, de constantes desafios e experimentações construídas a cada Congresso, a cada parceria com a diferente Comissão Local, a qual anima e organiza o encontro em diálogo e colaboração com a Diretoria Ampliada da ABA-Agroecologia. Partindo

1 Tecnóloga em Agroecologia (UFPR Setor Litoral), Assessora de Comunicação e integrante do GT de Cultura e Comunicação da ABAAgroecologia. E-mail:

luiza.damigo@gmail.com

2 Doutoranda em Ciências Sociais (IFCH/Unicamp) e integrante do GT de Cultura e Comunicação da ABAAgroecologia. E-mail:

natalia.almsouza@gmail.com

3 Professor do Programa de Pós graduação em Desenvolvimento Rural e Gestão de

Empreendimentos Agroalimentares do Instituto Federal de Educação,

Ciência e Tecnologia do Pará -

Campus Castanhal, Presidente da Associação Brasileira de

Agroecologia (ABA-Agroecologia).

E-mail:

romier.sousa.ifpa@gmail.com da compreensão da agroecologia enquanto ciência, movimento e prática, bem como da indissociabilidade do ensino, pesquisa e extensão, percebemos a necessidade de contextualizar as diferentes dimensões de nosso trabalho, a ciência e conhecimento que nos propusemos a partilhar.

Pensar sobre a trajetória do CBA, que no ano de 2003, em sua primeira edição, trouxe a conquista da Soberania Alimentar como tema central, é refletir sobre a história da própria ABA-Agroecologia, formalizada no ano seguinte, em 2004, durante o segundo CBA, em Porto Alegre. Naquele momento, havia a avaliação da necessidade de um espaço que agregasse o conjunto de pessoas que vinham construindo a Agroecologia e estavam nas Universidades, Institutos Federais (IFs), Centros de Pesquisas, Órgãos de Extensão rural e outras instituições de promoção do desenvolvimento rural.

Agora, em novembro de 2019, a ABA-Agroecologia completa 15 anos. Na trajetória, muitos desafios coletivos, sementes plantadas e colhidas em todo país. A participação na construção e na implementação de importantes políticas públicas, como os Núcleos de Estudos em Agroecologia (NEAs) e a Política Nacional de Agroecologia e Produção Orgânica (PNAPO); a contribuição científica em diversos espaços de governança social e política, como o Conselho Nacional de Segurança e Soberania Alimentar - CONSEA, a Comissão Nacional de Agroecologia e Produção Orgânica (CNAPO), além da Articulação Nacional de Agroecologia (ANA), são algumas das ações que marcam nosso caminho. 
A perspectiva da Agroecologia enquanto ciência hoje está presente no campo e na cidade, nas instituições públicas de ensino brasileiras, nas instituições de pesquisa e nas entidades de extensão rural.

A Agroecologia é um campo de conhecimento presente em mais de 160 cursos em Universidades e IFs no Brasil, mais de 200 NEAs, inúmeros grupos de pesquisa, coletivos de estudantes e em tantas outras ações de construção do conhecimento agroecológico realizadas no país. A ABA tem muito orgulho de ter contribuído para este crescimento a partir dos CBAs, dos GTs, dos Seminários sobre Educação e Agroecologia, do Projeto de Sistematização, da promoção da Revista Brasileira de Agroecologia e da parceria com diversas Universidades, EMBRAPA, Institutos e Organizações Não Governamentais.

Estruturada a partir de sua diretoria, vice-presidências regionais e grupos de trabalho, a associação atua em rede, nos territórios e em articulação com outras organizações, sejam elas do campo acadêmico ou não, e movimentos sociais. Desde os diversos pontos e laços das redes, colocamos em prática a ciência que ajudamos a construir e promover, uma ciência engajada, que compreende a necessidade do diálogo de saberes com as outras formas de produção do conhecimento em sociedade.

Os Grupos de Trabalho (GTs) se constituem como espaços permanentes de reflexão política, sistematização, troca e construção de conhecimento. Suas ações em rede impulsionam atividades, debates e estimulam articulações em diferentes esferas e escalas, reunindo profissionais, pesquisadoras(es), professoras(es), estudantes, agricultoras(es) e demais interessadas(os) que queiram conhecer os GTs e participarem de suas iniciativas.

São oito temas de estudo, reflexão e prática, com representantes de todo o país. Agrotóxicos e Transgênicos, Campesinato e Soberania Alimentar, Construção do Conhecimento Agroecológico, Cultura e Comunicação, Educação em Agroecologia, Gênero, Juventudes e Saúde. A sua gestão, assim como de toda a diretoria da associação, é definida e renovada a cada dois anos, na assembleia final do CBA.

Desse modo, em Assembleia são apresentadas as candidaturas para a realização dos CBAs, evento máximo de culminância das ações da ABA e seus associados, assim como, a possibilidade de diálogo sobre os avanços das pesquisas em agroecologia. Em 2017, o Estado de Sergipe foi escolhido para sediar o CBA de 2019, a partir da Rede Sergipana de Agroecologia (RESEA), com apoio de diversas organizações do Nordeste, como a Articulação do Semiárido Brasileiro (ASA). A partir daí, iniciamos um processo de construção muito rico, participativo e dinâmico, com o horizonte de um CBA democrático e popular, com os rostos e identidades das pessoas que têm promovido a agroecologia no Brasil, principalmente agricultoras(es) familiares camponesas(es), povos e comunidades tradicionais e indígenas.

Nessa lógica, foi proposto o lema do Congresso: "Ecologia de Saberes: Ciência, Cultura e Arte na Democratização dos Sistemas Agroalimentares". A ecologia de saberes vem sendo apresentada como um conjunto de epistemologias contra-hegemônicas à crença da ciência moderna, como única e verdadeira. Em que medida os conhecimentos ancestrais, a memória biocultural e as inovações camponesas têm sido consideradas na construção do conhecimento agroecológico que temos desenvolvido? A partir desta perspectiva, temos nos desafiado a articular a ciência, as práticas e o movimento, no sentido de uma Teia de saberes acadêmicos e populares.

A ideia da Teia é a inspiração para a construção metodológica deste CBA. Nas palavras da Comissão Metodológica Local: "A teia deve permitir atar nós entre as diferentes modalidades de trabalho, num mesmo eixo, mas também, atar nós entre os eixos. Os debates que permeiam o XI CBA devem emergir dos conteúdos, questões, denúncias, anúncios e proposições trazidos pelos artigos científicos, relatos técnicos e relatos populares, inclusive, aqueles em formato de vídeo".

Os GTs da ABA, bem como os Coletivos de Trabalho Temáticos da ANA, a exemplo do Coletivo Nacional de Agricultura Urbana e outros grupos e movimentos sociais, estão envolvidos com o desenho da Teia que terce a programação deste XI CBA. Essa arquitetura em rede demonstra o compromisso da 
ABA em reconhecer, também, os importantes aprendizados acumulados nos últimos Encontros Nacionais de Agroecologia (ENAs) e nos Encontros Nacionais da ASA-Brasil, além de muitos outros, assim construindo, cada vez mais, um Congresso dialógico e sintonizado com a diversidade das práticas realizadas pelos múltiplos sujeitos comprometidos com um projeto popular, democrático, feminista para a agroecologia, em especial, no Brasil e na América Latina, nossos territórios identitários.

Em um contexto político tão desafiador, realizar o CBA em uma Universidade Federal reforça e renova nossos vínculos com a educação pública, gratuita e de qualidade. Para que este Congresso seja viável, uma trama de esforços, muitas vezes invisível, segue mobilizada e, para a ABA-Agroecologia, está claro o compromisso da Comissão Local com os processos coletivos, solidários e diversos. Nessa edição do Congresso, novas experiências de interação, vivência, partilha de práticas e avanços conceituais nos convidarão a percorrer os ambientes, observando nossos temas de pesquisa e ação, assim como as interações entre eles e as diferentes linguagens possíveis no diálogo com a sociedade.

Teremos, assim, a integração de diversos espaços, todos considerados ambientes de Diálogo de Saberes, a exemplo dos Tapiris (apresentação e diálogo dos trabalhos), os Ambientes de Interação Agroecológica como as oficinas, vivências, rodas de conversa, círculos de cultura, instalações artísticopedagógicas, os Ambientes Político-Identitários, como as plenárias e reuniões quilombolas, indígenas, de jovens e de mulheres, e os Ambientes Permanentes, tais como o Terreiro das Inovações Camponesas, a Feira de Saberes e Sabores, a Ciranda infantil, o Espaço de Cura e Saúde, a Aldeia e a Cozinha das Tradições, a Casa dos NEAs, que irão compor espaços que nos convidarão para diferentes experiências vivenciais relacionadas ao que estamos chamando de Ecologia de Saberes, tema do nosso Congresso.

A agroecologia, essa ciência dos agroecossistemas, dos sistemas agroalimentares, dos lugares, diversa e imbricada em diferentes redes conceituais, saberes e práticas, também nos ensina que o Congresso será um momento de culminância. Diferentes universidades, NEAs, IFs, coletivos, fóruns e movimentos estão construindo atividades preparatórias ao XI CBA, possibilitando espaços de reflexão e elaboração coletiva dos relatos de experiências exercitando nossa prática enraizada nos territórios, no reconhecimento da autoria coletiva e solidária, mas, sobretudo, de estudo conjunto do lema do Congresso e dos desafios que estão apontados para o enfrentamento dos conflitos, defesa e fortalecimento da agroecologia, enquanto resistência dentro e fora das Instituições de Ensino, Pesquisa e Extensão no país.

Mesmo após a finalização do prazo para submissão dos relatos, esses encontros podem acontecer para que essas análises territoriais e estudos coletivos possam seguir e se aprofundar rumo ao Congresso. É somente no encontro, no diálogo e no fazer coletivo que encontraremos alternativas para os grandiosos desafios colocados a todas e todos nós.

Encerramos com agradecimentos ao Núcleo de Agroecologia da UnB que animou o processo de elaboração dessa edição especial da RBA e acolheu, no início deste ano, o Workshop sobre perspectivas do ensino, pesquisa e extensão em agroecologia no Brasil com auxílio da Fundação de Apoio a Pesquisa do Distrito Federal (FAP/DF), cuja parceria permitiu a realização de uma reunião ampliada da Diretoria da ABA-Agroecologia; em seguida, agradecemos à todos os GTs e grupos de pesquisa que contribuíram para essas reflexões e registros temáticos que compõem e qualificam as memórias tecidas pela ABAAgroecologia.

Agradecemos, com enorme satisfação, a Comissão Organizadora Local do XI CBA, pois a Rede Sergipana de Agroecologia vem nos ensinando muito e a ela dedicamos essa edição da RBA. A ousadia metodológica e compromisso desse grupo inspira e renova o fazer da ABA. Por fim, agradecemos a todas as organizações, grupos, redes, movimentos sociais e pessoas que constroem essa décima primeira edição do Congresso Brasileiro de Agroecologia. Seja no envio do trabalho, na composição das comissões descentralizadas de organização ou na participação ativa, solidária e parceira, esperamos rever cada um e uma de vocês em breve, em Sergipe, essa terra nordestina que pulsa resistência, criatividade e esperança! 